\title{
UM OLHAR PASTORAL AO DOCUMENTO DA CNBB SOBRE OS JOVENS: evangelização da juventude - desafios e perspectivas pastorais
}

\author{
Glaucio Luiz Mota \\ Graduado em Pedagogia pela Universidade do Estado de Santa Catarina, Pós-Graduando em \\ Juventude, Religião e Cidadania pelo Instituto de Teológico de Santa Catarina, Assistente de \\ Pastoral do Colégio Marista - Criciúma, Assessor da Pastoral da Juventude na Diocese de \\ Criciúma - SC, Criciúma, SC - Brasil, e-mail: gmota@marista.org.br
}

\section{Evangelização da juventude na ótica da CNBB}

Historicamente a juventude tem desempenhado papel de destaque na Igreja, seja como destinatária da evangelização, seja como presença evangelizadora e renovadora. Os jovens, segundo a CNBB - Conferência Nacional dos Bispos do Brasil, devem receber especial atenção devido a sua vulnerabilidade social. Ainda, para a CNBB, a sociedade apresenta à juventude "uma oferta imensa de experiências potenciais e de conhecimento, mas não lhes fornece recursos adequados para satisfazer suas aspirações". ${ }^{1}$ Para isso, a Igreja assume uma pastoral orgânica para a juventude "visando à formação das futuras lideranças sociais e políticas". (CNBB, 2003, p. 198).

Para consolidar essas afirmações, a Igreja Católica, representada pela CNBB, sente a necessidade de um pronunciamento oficial. Assim, temos: Evangelização da Juventude - Desafios e Perspectivas Pastorais. Brasília. Edições CNBB, 2007.

Diretrizes gerais da ação evangelizadora da igreja no Brasil 2003-2006, n. ${ }^{\circ} 198$. 


\section{A história do documento}

Alguns estudos da CNBB foram diretos na apresentação de temas relacionados à juventude: Pastoral da Juventude, n. ${ }^{\circ}$ 44, e o Marco Referencial da Pastoral da Juventude do Brasil, n. $^{\circ}$ 76, além de abordagens de outros temas como: a questão vocacional, a catequese, a educação. No entanto, até então, não havia nenhuma publicação oficial sobre a evangelização da juventude nas suas várias realidades e segmentos, com peso de documento e que englobasse todas as juventudes, inseridas ou não no meio eclesial.

Diante da pouca mobilidade do episcopado e da urgência em discutir a juventude, seus problemas e necessidades, a Conferência Nacional dos Bispos do Brasil escolhe, em 2005, aquele que seria o tema central da 44. ${ }^{a}$ Assembléia da CNBB, em 2006: A evangelização da juventude. Para tal, foi delegado um grupo escolhido pela CNBB que elaboraria instrumentos, os quais fundamentariam as discussões da assembléia acerca desse tema.

O resultado das discussões da assembléia foi convergido na publicação do estudo n. ${ }^{\circ}$ 93, intitulado: Evangelização da Juventude - Desafios e Perspectivas Pastorais. Tal documento foi disseminado nas bases eclesiais, para que retornasse com contribuições de jovens e especialistas em juventude a fim de que, na 45. ${ }^{\text {a }}$ Assembléia da CNBB, fosse mais uma vez apreciado pelos Bispos na possibilidade de ser aprovado e publicado como documento oficial da Igreja no Brasil e foi o que aconteceu.

\section{O que traz o documento}

É preciso antes de tecer qualquer crítica ao documento, seja ela positiva ou não, valorizar o pronunciamento, mesmo que tardio, do episcopado brasileiro diante dos clamores da juventude. Mesmo que o presente documento não trouxesse novidade, e ele traz, é preciso reconhecer a louvável iniciativa da CNBB em dirigir palavras aos jovens brasileiros.

O documento é divido em três partes. O primeiro capítulo, Elementos para o conhecimento da realidade dos jovens, traz questões históricas e culturais da modernidade e da pós-modernidade e o perfil socioeconômico e religioso da juventude. Além disso, demonstra o relato da experiência acumulada da Igreja na evangelização da juventude. O segundo capítulo, Um olhar da fé a partir da 
palavra de Deus e do magistério, apresenta o olhar teológico sobre a juventude à luz da palavra de Deus. E o terceiro, Linhas de ação, traz pistas concretas para a evangelização da juventude.

\section{Conhecendo os jovens e as juventudes}

A evangelização exige conhecimento da realidade de quem se deseja evangelizar. Essa é uma lógica que não se dispensa ainda mais em se tratando da juventude. O documento começa falando da realidade juvenil, levando em conta que essa fase da vida é tomada pela inconstância, pelas limitações e por potencialidades. Essas características são contextualizadas com as constantes mudanças sociais, históricas e culturais no mundo.

De um lado, apresenta-se a cultura moderna caracterizada pela "centralidade da razão, a liberdade, a igualdade e a fraternidade"(CNBB, 2007, p. 11). De outro lado, apresenta-se a cultura pós-moderna com "mudanças no cenário, velocidade e volume da informação, a rapidez com que a tecnologia mudou o cotidiano, novos códigos e comportamentos" (CNBB, 2007, p. 12).

Diante destas possibilidades culturais, a primeira questão pertinente que o documento traz diz respeito à busca de equilíbrio entre a razão e a emoção introduzidos na sociedade pela modernidade e a pós-modernidade. Esse pressuposto da evangelização levanta a seguinte pergunta: como a evangelização da juventude poderá contrapor os problemas trazidos pela subjetividade, pelo pluralismo religioso e pela centralidade das emoções?

A subjetividade na sociedade atual tem moldado um perfil de ser humano cada vez mais centrado em si mesmo e insensível às causas coletivas. A partir dessa lógica, a vida humana, muitas vezes, é encarada de forma fria e inescrupulosa. O imediatismo, influenciado pela subjetividade, cria a idéia de que tudo é descartável, desde os produtos de consumo até a vida humana.

Essa idéia acaba gerando mudanças até na própria religiosidade que, de prática coletiva, passa a ser uma prática individual fazendo com que a fé não seja mais professada de forma institucional. Essa afirmação é comprovada pelo fato de que muitos jovens possuem uma aversão aos entraves burocráticos e conservadores que a instituição eclesial impõe a eles.

Diante disso, o documento reflete as novas expressões da vivência do sagrado como fuga de tais incertezas humanas e como busca da realização de suas próprias necessidades. É a partir dessa realidade que entendemos o 
surgimento de inúmeras denominações religiosas cristãs com doutrinas que se adaptam a partir do que os seus "clientes" desejam consumir espiritualmente. Com isso, deixam de lado a fidelidade ao evangelho criando uma espiritualidade que satisfaça somente as necessidades de seus fiéis.

Outra questão que essa primeira parte do documento apresenta é justamente uma das saídas de igrejas e religiões para manter seus adeptos, que seria a apelação para o emocional. A centralidade das emoções, um outro aspecto refletido no documento, aponta metodologias as quais usam o aspecto emotivo e subjetivo por parte das igrejas neopentecostais. Seria interessante ressaltar que o documento não faz menção aos movimentos católicos que também se utilizam dessa prática. Talvez como estratégia política, o que seria uma contradição, ou por imaginar que isso ocorrerá de forma pedagógica ao longo do processo evangelizador proposto por esse documento.

Na sequência do primeiro capítulo, o perfil da juventude brasileira relata essa fase da vida que possui a face das incertezas, dos desafios e das potencialidades. Seria de suma importância que cada evangelizador conseguisse levar em conta todas estas características juvenis. Tanto o clero como as lideranças leigas, sobretudo adultos, ainda possuem certa ignorância com relação ao fenômeno juvenil desconsiderando aspectos sociais, culturais e econômicos importantes para a evangelização da juventude. Nesse sentido, uma atitude importante seria encarar o jovem não somente como "ovelha perdida" que merece cuidados paternalistas, mas como pessoa que precisa ser empoderada para resistir às pressões que o sistema neoliberal lhes impõe proporcionando, assim, autonomia e emancipação.

A juventude brasileira, em torno de 47 milhões, possui inúmeras dificuldades. Por conta disso, precisaria ser mais valorizada, até porque esse grupo populacional consiste em uma potencial de massa produtiva para o desenvolvimento do país.

Outro aspecto que necessitaria ser abordado de forma mais ampla pelo documento seriam os problemas emocionais que a juventude apresenta face à falta de estrutura familiar. A família é uma temática inevitável nos debates sobre os problemas enfrentados pelos jovens, por isso, mereceria mais destaque.

Outro ponto que aparece no primeiro capítulo demonstra como se dá o protagonismo e a participação social do jovem. Para entender estas questões é importante saber como a sociedade concebe a juventude. As propagandas e novelas promovem um tipo de jovem esteticamente perfeito, saudável, sem problemas e despreocupado. Já os noticiários mostram jovens, principalmente 
negros e pobres, envolvidos em problemas de toda ordem. Essas características são agregadas ao senso comum de que toda a juventude é "individualista, consumista e politicamente desinteressada" (CNBB, 2007, p. 37).

A pesquisa apresentada no documento acaba afirmando tal pensamento, mas também aponta outras formas de participação juvenil e chama a atenção para falta de espaços adequados para o engajamento social da juventude. É importante ressaltar que a própria Igreja não acolhe bem os jovens, o que acaba construindo seu perfil religioso caracterizado por uma crença desvinculada da instituição religiosa. Marca disso está no desligamento do jovem das tradições religiosas familiares.

Ainda sobre o perfil religioso do jovem, um reconhecimento visto no documento refere-se à falta de uma proposta evangelizadora para os adolescentes, os quais precisam de um espaço diferenciado para quem está nesta fase da vida.

Apesar destas limitações o documento ressalta, com toda razão, a importância das manifestações juvenis nas comunidades de base e nas paróquias onde os jovens participam ativamente de vários setores, pastorais, movimentos e outras iniciativas eclesiais.

Fechando o primeiro capítulo, o documento aborda o valor da experiência acumulada da Igreja como fonte riquíssima de aprendizado pastoral. Por meio desse legado histórico, é possível vislumbrar um horizonte que é construído com o acúmulo de experiências da Igreja realizadas com erros e acertos. Assim, pode-se pensar e adaptar a evangelização para os dias atuais.

\section{A juventude como lugar teológico}

Quando se houve falar em evangelização da juventude, tal tema poderia soar despretensioso, passando a idéia de que a juventude é mera receptadora da evangelização. Mesmo o jovem pouco conhecedor da teologia, da filosofia e da metodologia pastoral, seria ele, também, capaz de evangelizar?

O segundo capítulo do documento Evangelização da Juventude, Um olhar da fé a partir da palavra de Deus e do Magistério, apresenta pressupostos teológicos para a evangelização da juventude na comunidade cristã.

O pressuposto, O seguimento a Jesus Cristo aponta a característica cristocêntrica da Igreja. Jesus é o "caminho, verdade e vida". A Igreja deve apresentar ao jovem o Cristo que caminha junto com ele, que o escuta e lhe traz 
respostas para "as suas angústias e aspirações mais profundas" (CNBB, 2007, p. 54). Todo jovem é chamado a ser discípulo a partir do exemplo de Maria, seguidora de Jesus Cristo, e, desse modo, assim como ela, ser um evangelizador.

Outro pressuposto apresentado no segundo capítulo, Igreja, comunidade dos discípulos de Jesus, aponta a Igreja comunidade como principal lugar de evangelização.

Infelizmente o jovem na comunidade, muitas vezes, além de não ser bem acolhido, vê a Igreja somente como instituição burocrática e conservadora, sem percebê-la como lugar de comunhão e evangelização. Essa é uma advertência para a forma como mostramos a Igreja para a juventude.

Além disso, uma importante ressalva faz o documento com relação ao espaço dado ao jovem nas instâncias de decisões. Inserir o jovem na Igreja não é tratá-lo como mero coadjuvante, mas é permitir que ele deixe sua marca criativa e inovadora nos vários espaços eclesiais.

Em seguida, é lançada uma questão que talvez seja a mais importante do documento: "O jovem necessita não somente que falemos para ele de um Deus que vem de fora, mas de um Deus que é real dentro dele em seu modo juvenil de ser alegre, dinâmico, criativo e ousado" (CNBB, 2007, p. 80). Com essa afirmação, a Igreja reconhece no jovem um lugar teológico. Isto abre, profeticamente, possibilidades de mais abertura da Igreja para o mundo juvenil.

Com esse pensamento, a juventude é encarada como uma fonte teológica até nos erros cometidos, pois nos permite aprender com eles e nos humaniza ao ponto de causar transformações em nossas ações pastorais; estas mudanças são boas, não somente para os jovens, mas para toda a Igreja.

O pressuposto seguinte, Construção de uma sociedade solidária, reafirma a missão da Igreja de colaborar na construção de um mundo mais justo e fraterno. Para isso, a juventude deverá ampliar seu próprio campo de relações afetivas para outras mais amplas e globais. A ação evangelizadora precisa contemplar a dimensão sócio-política do jovem para que ele seja promotor da cidadania plena para todos, sobretudo os mais necessitados.

Essa afirmação, teoricamente, teria que mudar a postura de certos movimentos eclesiais que acentuam sua metodologia em aspectos emocionais e acabam promovendo a alienação de seus participantes para as questões políticas. Mas, na prática, o que vemos é o crescimento de jovens que aderem a esse tipo de metodologia. A resposta da Igreja para essa insistência não está no documento. 
Por fim, o capítulo se encerra com Pronunciamentos do magistério sobre a juventude. Aqui o documento lembra as palavras de João Paulo II, na encíclica Christifideles Laici, que retoma o Concílio Vaticano II, afirmando que a Igreja tem muito a dizer para os jovens e esses tem muito a dizer à Igreja. Essa dialogicidade deve se materializar por meio de "uma autêntica pastoral de juventude" (CNBB, 2007, p. 89).

\section{Evangelizando a juventude de forma concreta}

A evangelização precisa ser pensada como um processo que leve em conta todas as dimensões do ser humano. Na terceira e última parte do documento são apresentadas linhas de ação para a evangelização da juventude. Estas linhas pressupõem um processo que possibilite a cada jovem a construção do seu projeto de vida e sua participação na edificação do reino definitivo. As linhas são as seguintes:

\section{1) Formação integral do discípulo}

Nessa linha de ação, é reconhecida uma opção pedagógica utilizada pelas Pastorais da Juventude há muito tempo que é a formação integral. Evangelizar a juventude, considerando o jovem como um todo, possibilita que não se reduza a formação a uma de suas dimensões, pelo contrário, devemos considerar cada dimensão, seja pessoal, comunitária, teológica, sócio-políticoecológica e de capacitação.

Dentro das pistas sugeridas para esta linha de ação, é importante ressaltar a conscientização vocacional na construção do projeto de vida. O documento não cita, mas vale dizer que a parceria com o Serviço de Animação Vocacional (SAV) é de suma importância. Para isso, a SAV deverá ampliar ainda mais seu alcance pastoral para que não se resuma somente em trabalhar com as vocações religiosas e sacerdotais.

Outra pista importante está na organização da Catequese Crismal. Não só na organização, mas na prática dessa idéia que existe há tempos e que pouco é ressignificada. 
Uma possibilidade que se renova é a de promover a formação integral nas escolas as quais são ambientes muito propícios para a evangelização.

E, por fim, aparece uma pista que motiva o envolvimento mais intenso da família na formação dos jovens; o que é de muito valor.

\section{2) Espiritualidade}

Essa linha de ação apresenta instrumentos para o exercício da espiritualidade que são: a oração pessoal, a oração comunitária, a participação na comunidade, a leitura orante da Bíblia, a vivência dos sacramentos, a devoção a Nossa Senhora, os diversos encontros espirituais e as leituras e reflexões.

As pistas de ação não oferecem novidades aos que já tem prática pastoral com juventudes, porém cabe ressaltar o incentivo ao uso do ofício divino da juventude, o qual é um instrumento novo construído a partir das experiências das Pastorais da Juventude do Brasil.

\section{3) Pedagogia da formação}

Essa linha de ação apresenta quatro desafios e princípios orientadores para desenvolver uma pedagogia de formação a partir de experiências já consolidadas da Igreja no Brasil e na América Latina. Os desafios e princípios orientadores são: a) prioridade da experiência sobre a teoria; aqui se fala de método para evangelização. A pedagogia de Jesus é a fonte para metodologia da evangelização. O método ver-julgar-agir-revisar-celebrar aparece como ferramenta para isso; b) pedagogia de pequenos grupos e eventos de massa, que reflete estas duas formas de evangelização. Os eventos de massa, como as Jornadas Mundiais da Juventude, o Dia Nacional da Juventude, são eventos que causam um efeito positivo e motivador nos jovens. Aqui cabe lembrar, novamente, que é necessário "garantir que os eventos de massa se integrem num processo contínuo de educação na fé" (CNBB, 2007, p. 153); c) níveis de evolução do processo de acompanhamento dos jovens. As Pastorais da Juventude entendem está dialética como processo de educação na fé e que acontecem por etapas. O termo evolução, usado no documento, pode não ser uma boa forma de falar desse processo; d) conscientizar os jovens sobre o projeto pastoral para a juventude. Esta questão é extremamente necessária, pena que nem todos os trabalhos com juventude são projetados com fundamentos pastorais. 
Entre as pistas de ação, vale ressaltar o acompanhamento sistemático dos grupos. Seria interessante se todas as paróquias e comunidades investissem na formação de assessores para esse serviço e desmistificasse idéias como: qualquer pessoa pode acompanhar um grupo de jovem, principalmente casais. Além de critérios como testemunho cristão, é preciso que o assessor identifique-se com os jovens e tenha formação pedagógico-pastoral específica para esse serviço.

\section{4) Discípulos e discípulas para a missão}

Eis uma questão importante para a ação pastoral, o aspecto da missão. A evangelização sobre a lógica pastoral remete ao encontro com o outro, sobretudo com aqueles que não estão inseridos na Igreja. Seria muito fácil se propor a evangelizar somente os jovens que já participam da comunidade eclesial. É de suma importância que o jovem tenha essa compreensão para que possa evangelizar outros jovens fora do seu "gueto". Outro ponto importante da missionariedade, citada no documento, diz respeito a uma evangelização que não tenha somente a intenção de trazer o jovem à Igreja, mas também o motive a incluir, em seu projeto de vida, a vocação de ser agente transformador na sociedade.

As pistas dessa linha de ação não apresentam novidades. Elas motivam para a prática do projeto "Missão Jovem", ${ }^{2}$ para ir ao encontro da diversidade de jovens e para a participação na comunidade eclesial e na sociedade.

\section{5) Estruturas de acompanhamento}

Essa linha de ação traz a questão que, para muitos, é a mais polêmica do documento: o Setor Juventude. O Setor Juventude já existe em âmbito nacional, mas não é citado nesta linha de ação. O Setor da juventude nacional funciona há algum tempo, mas nunca recebeu pleno reconhecimento por parte das lideranças que trabalham com juventudes. As questões políticas que afetaram o Setor sempre limitaram a sua eficácia como articulador de idéias. $\mathrm{O}$ documento acena para o funcionamento da estrutura de setor em âmbito diocesano e paroquial. Espera-se que essa possibilidade possa ser eficaz, justamente por estar organizado em regiões menores, o que facilita muito mais a operacionalização de ações e projetos.

Versão juvenil das missões populares. 
Quanto às estruturas para promover a comunhão entre as forças vivas das juventudes, é oportuno que as dioceses articulem um debate muito aprofundado sobre o setor juventude para que se tenha clareza do que se almeja com essa instância; de sua pertinência ou não. O Setor Juventude poderá ter sentido se contribuir de fato com a evangelização da juventude e, até mesmo, com a evangelização de quem participará desse setor. "A intenção deste setor não deverá ser a unificação dos trabalhos, mas criar comunhão entre os evangelizadores da juventude". 3

\section{6) Ministério da Assessoria}

Há muito tempo os especialistas, os assessores e os próprios jovens vem alertando sobre a fragilidade no trabalho de acompanhamento aos jovens. Há um pequeno número de assessores os quais muitos destes não possuem formação ideal.

$\mathrm{O}$ documento reconhece a assessoria como um ministério. De fato, o processo de educação na fé dos jovens, de forma individual e em grupo, exige um acompanhamento sistemático. A pessoa do assessor é fundamental, sobretudo nas primeiras etapas desse processo. "Faz-se necessário para tal o preparo de pessoas que tenham clareza do projeto pastoral e da metodologia para chegar aos jovens e envolvê-los num processo de educação na fé" (CNBB, 2007, p. 205). Seria muito bom para a evangelização da juventude que as dioceses e outros organismos passassem a investir ainda mais em pessoas com esse perfil.

\section{7) Diálogo fé e razão}

Há algum tempo o espaço da Igreja nas universidades é perdido por falta de um trabalho sistematizado. A Pastoral Universitária já não possui a mesma força e organização de anteriormente, estando apenas presente de forma fragmentada em algumas universidades. Há boas experiências em universidades católicas a partir dos carismas das congregações que as administram, porém são poucas perto do grande número de universidades no Brasil.

Por ser a universidade importante espaço para o diálogo fé e razão, é missão da Igreja, provocar nos jovens universitários, diante do contexto pósmoderno, um debate contínuo "para que saibam se mover de maneira crítica dentro do mundo intelectual, acompanhados de uma visão cristã autêntica para que possam

Neusa Mafra no Estudo do Documento 85, na Diocese de Criciúma - SC. 2007. (Não publicado). 
atuar responsavelmente no mundo do qual fazem parte" (CNBB, 2007, p. 218). Essa afirmação não apresenta novidade, entretanto é de fundamental importância que seja retomada e repensada a evangelização da juventude nas universidades.

\section{8) $\mathbf{O}$ direito à vida}

Como já foi escrito inicialmente, a vulnerabilidade social na fase da juventude nos interpela a uma firme atuação na busca dos direitos essenciais dos jovens, como: "à educação, ao trabalho e à renda, à cultura e ao lazer, à segurança, à assistência social, à saúde e à participação social" (CNBB, 2007, p. 230). O documento reforça que tais direitos são fundamentais para que o próprio jovem venha assumir uma postura cidadã, buscando maior responsabilidade sobre si mesmo e com a sociedade.

As políticas públicas são apresentadas como importante instrumento de garantia de direitos. Mesmo sendo de responsabilidade do Estado, todo cidadão consciente deve desempenhar seu papel no processo de criação e de fiscalização das políticas públicas.

Nas pistas de ação, merece destaque o estímulo que o documento dá ao debate das questões que geram desigualdades sociais as quais tem ligação com a juventude. A Doutrina Social da Igreja aparece como um importante fundamento para compreensão e para possíveis ações sociais. E, por fim, é urgente a valorização da família como primeiro espaço de formação do jovem cidadão.

\section{Conclusão}

O documento em si é muito oportuno, essencial para o contexto histórico em que vivemos; mais ainda para a juventude, a qual atravessa uma importante e desafiadora fase da vida. Por isso, mesmo que o episcopado brasileiro, de certa forma, tenha demorado em fazer um pronunciamento à juventude do país, é muito louvável a publicação desse documento, tenha ele trazido grandes novidades ou não.

A realidade dos jovens, que é bastante diversificada, exigia uma posição sistematizada com princípios e pistas à evangelização da juventude. Esse documento, acredito, apesar de ser passível de muitas melhoras, consegue, no mínimo, despertar um debate no seio da Igreja sobre a evangelização dos jovens e, isso, por si só, já seria de grande valia. Além disso, o documento suscita 
esperanças nos jovens e naquelas inúmeras pessoas que se dedicam à causa da juventude. São esses que, possivelmente, suspiram quando o documento, de forma muito feliz, apresenta a juventude como lugar teológico. Tal afirmação compromete cada evangelizador a ter um olhar mais pedagógico sobre a juventude a partir de um projeto claro de pastoral. Para isso, cada evangelizador precisará entender a juventude no seu todo, em suas dificuldades e potencialidades.

As linhas de ação propostas dão instrumentos à evangelização dos jovens e, por conta disso, merecem um olhar carinhoso e crítico para que essas linhas possam contribuir efetivamente no processo de educação na fé da juventude. Especial atenção merece a pista de ação setor juventude. Essa linha de ação não pode ser encarada como uma ação pontual, mas como uma ação muito bem planejada para que venha dar resultados benéficos à evangelização da juventude.

De um modo geral, esse documento traz mais expectativas positivas do que angústias. O documento se propõe a criar processos sem trazer receitas prontas e motiva o envolvimento de todos na construção de um projeto de pastoral forte, fundamentado no projeto maior que é o de Jesus Cristo. Pensando com essa lógica, um belo e desafiador horizonte se desenha a nossa frente. Que saibamos enxergar as luzes do Espírito Santo que nos guia nesse caminho junto aos jovens.

\section{Referências}

CONFERENNCIA NACIONAL DOS BISPOS DO BRASIL - CNBB. Diretrizes gerais da ação evangelizadora da igreja no Brasil 2003-2006. São Paulo: Paulinas, 2003.

Evangelização da juventude: desafios e perspectivas pastorais. Brasília: CNBB, 2007.

MAFRA, N. Estudo do Documento 85, na Diocese de Criciúma -SC. 2007. (Não publicado). 